\title{
A Atuação dos Residentes Multiprofissionais; Acolhimento, Articulação em Rede e Trabalho em Equipe.
}

\author{
Pereira, Alessandra Keyth; Berach, Flávia Rúpolo; Pfuetzenreiter, Nataniele P. B.; Netto, \\ Maria Carolina; Amorim, Simone Cristina de; Regis, Tatiana Rivas \\ Universidade Federal de São Paulo — alessandrakeyth@gmail.com
}

\begin{abstract}
INTRODUÇÃO: o Programa de Residência Multiprofissional sobre o qual relataremos objetiva articular demandas dos usuários do Sistema Único de Saúde (SUS) aos equipamentos da rede, integrando um propósito de aprendizagem e um processo de formação profissional que vai além dos conhecimentos específicos. a construção desse processo torna-se possível pelo trabalho em equipe, no qual a lógica é olhar por diferentes perspectivas que devem se integrar, caminhando em direção a outros modelos de cuidado que colocam em questão a atuação fragmentada na atenção à saúde, garantindo a aplicação dos princípios e diretrizes do SUS na prática. OBJETIVO: Caracterizar o processo de trabalho dos residentes no programa de residência multiprofissional. MÉTODO: Relato de experiência dos residentes das áreas profissionais de educação física, enfermagem, farmácia, fisioterapia, nutrição, psicologia, serviço social e terapia ocupacional. RESULTADOS: Buscou-se um processo de trabalho no qual os projetos terapêuticos formulados pudessem transcender a lógica biomédica e assim focar no usuário e em suas reais necessidades, apostando no trabalho interprofissional, na qualificação das práticas de acolhimento e de articulação com a rede de serviços. para tal finalidade lançou-se mão de estratégias como: a ampliação do setting terapêutico, proporcionando espaços de escuta em outros ambientes além do leito hospitalar e dos consultórios nas Unidades Básicas de Saúde; a compilação de dados sobre os serviços existentes na rede em diversas linhas de cuidado; a participação em discussões de caso com equipes de diferentes serviços; o reconhecimento dos territórios de atuação; e a criação de instrumentos que potencializaram os fluxos de referência e contrarreferência. o processo de cuidado estabelecido facilita a aprendizagem dos envolvidos, na medida em que amplia o olhar do indivíduo e seu entorno, a partir da troca de saberes entre usuários e profissionais. a organização e articulação da rede intersetorial do município apresenta entraves na comunicação e compreensão dos papéis dos serviços de saúde, educação e assistência, dificultando o compartilhamento dos saberes das diferentes áreas e a corresponsabilização dos profissionais pelo cuidado, demandando uma disponibilidade em relacionar-se, nem sempre presente entre os profissionais envolvidos. CONCLUSÃO: a aproximação da equipe com os usuários acontece por meio de uma interprofissionalidade que, de um lado, realiza o acolhimento disponibilizando um espaço-tempo de criação de laços e escuta prospectiva e, de outro, o encaminha e aproxima dos equipamentos sociais e de saúde, além de auxiliá-lo, se necessário, a fortalecer seus vínculos pessoais. para tanto consideram-se importantes: a criação dos processos de trabalho em equipe, a divisão de tarefas, a corresponsabilização dos pares e a devolutiva das atividades que estão em curso para o coletivo.
\end{abstract}

Pereira, Alessandra Keyth; Berach, Flávia Rúpolo; Pfuetzenreiter, Nataniele P. B.; Netto, Maria Carolina; Amorim, Simone Cristina de; Regis, Tatiana Rivas. A Atuação dos Residentes Multiprofissionais; Acolhimento, Articulação em Rede e Trabalho em Equipe.. In: Anais do Congresso Internacional de Humanidades \& Humanização em Saúde [= Blucher Medical Proceedings, num.2, vol.1]. São Paulo: Editora Blucher, 2014. ISSN 2357-7282

DOI 10.5151/medpro-cihhs-10605 